\title{
Experimental study on the particle flow patterns in a cyclone dipleg with a trickle valve
}

\author{
Chao-Yu Yan ${ }^{1} \cdot$ Guo-Gang Sun ${ }^{1} \cdot$ Jian-Yi Chen $^{1} \cdot$ Yao-Dong Wei ${ }^{1} \cdot$ Chun-Xi Lu ${ }^{2}$
}

Received: 30 August 2019 / Published online: 28 April 2020

(c) The Author(s) 2020

\begin{abstract}
An experimental apparatus including a dipleg and a trickle valve was established to simulate the operation of a suspended dipleg-trickle valve system of cyclone used in fluid catalytic cracking (FCC) unit. The flow regimes in the dipleg and the discharge modes in the trickle valve were studied by combining the observation of experimental phenomena with the analysis of transient pressure fluctuation. The results show that the flow regimes in the dipleg have two types-the dilute-dense phase coexisting falling flow and the dilute falling flow. Correspondingly, the trickle valve also has two discharge modes-the intermittent periodic dumping discharge and the continuous trickling discharge. The power spectrum density of pressure fluctuation displays that the gas-solids flow in the dipleg-trickle valve system is characterized by a low-frequency pulsation. The coherence coefficient explains the origin and propagation of pressure fluctuation in the system. Eventually, a map describing the flow regimes and discharge modes related to the operation parameters was proposed, which can provide a helpful guidance for the operation of cyclone dipleg-trickle valve system in FCC unit.
\end{abstract}

Keywords Cyclone dipleg $\cdot$ Trickle valve $\cdot$ Flow regime $\cdot$ Discharge mode $\cdot$ Pressure fluctuation

$\begin{array}{ll}\text { List of symbols } \\ D & \begin{array}{l}\text { Inner diameter of dipleg }(\mathrm{m}) \\ G_{\mathrm{s}}\end{array} \\ h & \begin{array}{l}\text { Solids flux }\left[\mathrm{kg} /\left(\mathrm{m}^{2} \mathrm{~s}\right)\right] \\ \text { Sealing height, or axial position in dipleg } \\ (\mathrm{m})\end{array} \\ \Delta P & \text { Negative pressure }(\mathrm{kPa}) \\ P_{x}^{*}(f), P_{y}^{*}(f) & \begin{array}{l}\text { The conjugate complex of } P_{x}(f) \text { and } P_{y}(f), \\ \text { respectively }\end{array} \\ P_{x}(f), P_{y}(f) & \begin{array}{l}\text { Fourier transformation of signals } P_{x}(t) \\ \text { and } P_{y}(t) \text { over the sampling time interval, } \\ \text { respectively }\end{array} \\ P_{x x}(f), P_{y y}(f) & \begin{array}{l}\text { Auto-power spectral of signals } P_{x}(t) \text { and } \\ P_{y}(t), \text { respectively }\end{array}\end{array}$

Edited by Xiu-Qiu Peng

Guo-Gang Sun

ggsunbj@163.com

1 Beijing Key Laboratory of Process Fluid Filtration and Separation, College of Mechanical and Transportation Engineering, China University of Petroleum-Beijing, Changping, Beijing 102249, People's Republic of China

2 State Key Laboratory of Heavy Oil Processing, College of Chemical Engineering and Environment, China University of Petroleum-Beijing, Changping, Beijing 102249, People's Republic of China

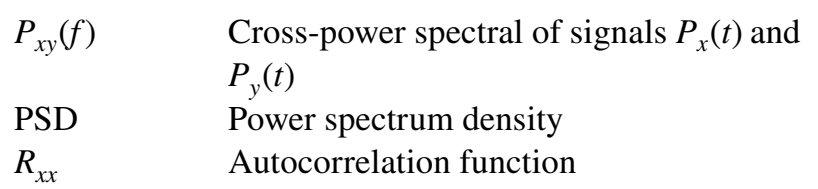

\section{Introduction}

Fluid catalytic cracking (FCC) is an important refinery process for converting heavy oil into more valuable gasoline and lighter products. A typical property of FCC unit is that the catalyst particles are required to keep a continuous and steady circulation flow along a designed loop between reactor and regenerator system. For the purpose, the catalyst particles should be efficiently separated from hydrocarbon vapors in the reactor and from flue gas in the regenerator by cyclone separators and be conveyed back to fluidized beds through diplegs. Usually, two stages of cyclone separators (primary and secondary cyclone) in series are installed in the freeboard above the dense bed of disengager and regenerator, respectively, as shown in Fig. 1. A dipleg is a pipe connected with the bottom hopper of a cyclone separator, which is used to convey the catalysts back to the dense bed from 


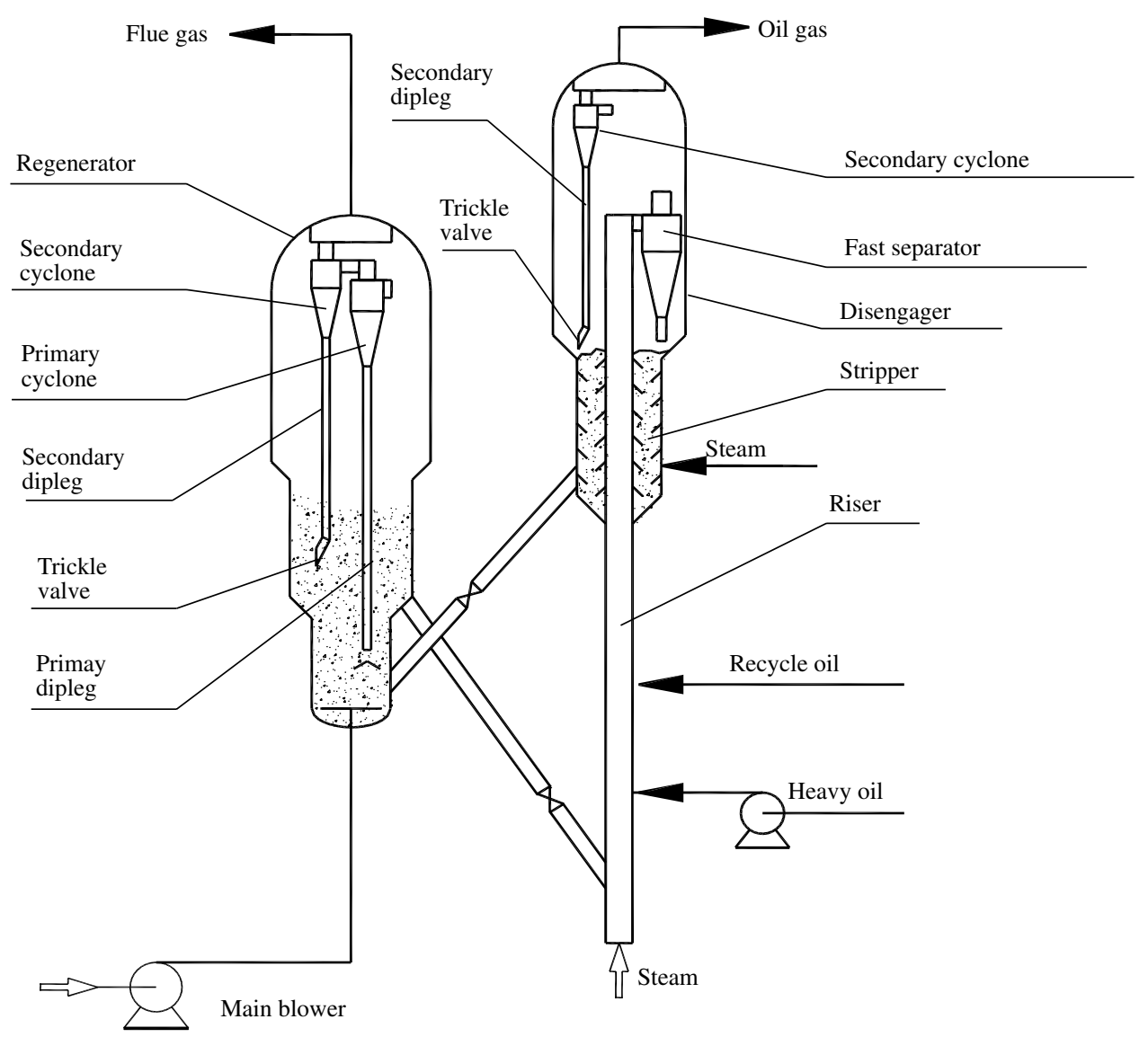

Fig. 1 Schematic diagram of FCC unit

a low-pressure top section of the dipleg to a high-pressure bottom region by particle gravity, as well as maintaining a seal to prevent the gas from flowing into the dipleg (gas leakage). If large quantity of gas flows up into the cyclone due to the gas leakage, the separation efficiency of the cyclone will decrease, and the loss of catalyst particles will happen. Therefore, the operation status of the dipleg has a great effect on the cyclone performance.

Generally, due to different inlet solids loading in gas-solids mixture flowing through the two stages of cyclones, the operation status of primary cyclone dipleg is usually different from that of the secondary dipleg. For the primary cyclone dipleg, over $99 \%$ of the separated particles flow down the primary cyclone dipleg, which has enough momentum to overcome negative pressure and prevent from gas leakage as well (Reddy Karri and Knowlton 2004; Geldart et al. 1993). So, the bottom end of primary cyclone dipleg is often opened without any valve and submerged in the dense bed (submerged dipleg) (Smolders et al. 2001) as shown in Fig. 1.

However, for the secondary cyclone dipleg, less than $1 \%$ of the separated particles flow through the secondary cyclone dipleg, which does not have enough seal ability to prevent gas leakage (Reddy Karri and Knowlton 2004; Geldart et al. 1993). Therefore, a trickle valve, which had been proposed by DuconCompay and widely used in many FCC units at present, is usually needed to attach to the bottom end of the secondary dipleg to minimize the gas leakage during the startup and other running periods of cyclone separator. And the trickle valve of the secondary dipleg can operate at a status of either submerged in the dense bed or suspended at the freeboard region above dense bed surface (Smolders et al. 2001). For more safety, the trickle valve is often submerged in the dense bed of regenerator (here called as submerged dipleg-trickle valve as shown in Fig. 1). However, due to the space limitation caused by the existence of bottom stripper in the disengager, the secondary dipleg-trickle valve cannot be inserted into the dense bed and often only can be suspended in the freeboard (here called as suspended diplegtrickle valve as shown in Fig. 1).

The production practice of FCC unit shows that some trouble shooting of catalysts loss could ascribe to the malfunction of the suspended dipleg-trickle valve operation (Niccum 2010). The probable malfunction of suspended secondary dipleg-trickle valve in the disengager is more easily happened than that of submerged dipleg-trickle valve in the 
regenerator by some causes, such as the gas leaking and the erosion of sealing flapper surface (Shaw and Walter 2007). Therefore, for the sake of the reliable design and operation of the suspended secondary cyclone dipleg-trickle valve in FCC disengager, the research on the flow regimes in the dipleg and the discharge modes in the trickle valve should be carried out systematically.

The FCC cyclone dipleg is really an overflow standpipe (Smolders and Baeyens 1995; Bouma 1998). Although the FCC cyclone dipleg is a very simple vertical pipe, the gas-solids two-phase flow in it is very complicated. Many factors, including the effect of swirling flow at the bottom outlet of cyclone, the negative pressure gradient flow of particles, and the capacity of solids conveying, make the FCC cyclone dipleg either different from the conventional vertical standpipe or the downcomer of circulating fluidized beds (Li et al. 1997). The studies on conventional standpipe and downcomer have many literature reports about the explanation of flow regimes and flow instability (Leung and Wilson 1973; Leung and Jones 1978; Li 2005; Jing and Li 1999; Zhang and Rudolph 1998; Mountziaris and Jackson 1991). However, in spite of the wide application of the cyclone dipleg in FCC and other industry units, little research work has been done about it so far.

The basic flow parameters (such as particle velocity, particle concentration, and pressure drop) in dipleg have the characteristics of dynamic nonlinear fluctuation, which leads to the complexity of flow regimes and flow instability in dipleg; for example, there are more than one flow regime coexisting in dipleg (Hoffmann and Stein 2002; Cortés and Gil Cortés and Gil 2007). Dries and Bouma (1997) divided the flow regimes into four regions along the axial direction of dipleg, inlet swirling flow, dense flow, fluidized flow, and packed flow. Wang et al. (2000a, b) thought that the dipleg could generally operate in one of three basic flow regimes, packed bed, fluidized bed flow, and a dilute flow called streaming flow. The experimental results by Smolders et al. (2001), Geldart and Radtke (1986) and Wei et al. (2003, 2004) showed that the primary cyclone dipleg in FCC was operated under a dense conveying flow regime due to a high solids flux; however, the secondary cyclone dipleg was operated mainly under a dilute-dense coexisting flow regime due to a low solids flux and a high negative pressure. In recent literatures, the study by Wei et al. (2016) showed that the flow regimes in the primary cyclone dipleg could be divided into two types based on the solids flux and negative pressure, the dilute-dense coexisting falling flow, and the dense conveying flow along the dipleg. However, these research results are mainly focused on the submerged dipleg. The study on the suspended dipleg-trickle valve is rarely involved.

In fact, for the suspended dipleg-trickle valve, the discharge modes in trickle valve are closely related to the flow regimes in dipleg. So, the relationship between the flow regimes in the dipleg and the discharge modes in the trickle valve should be studied simultaneously with a same set of experimental apparatus. However, the research work is very little despite their importance to FCC processes so far. In the literatures that could be retrieved, only several researchers reported their findings. Bristow and Shingles (1989) proposed four discharge modes of trickle valve, the trickling, the dumping, the trickling/dumping, and the flooding. Geldart et al. (1993), Sun et al. (2001) and Reddy Karri and Knowlton (2004) analyzed the operation of trickle valve. Especially, a blowing mode of trickle valve will occur when operating with positive pressure. In these trickle valve operation studies, Bristow and Shingles (1989) and Geldart et al. (1993) used batch solids transfer system that would operate continuously for a certain length of time. However, the investigation by Sun et al. (2001) and Reddy Karri and Knowlton (2004) used continuous solids transfer system, which is more capable of showing the evolution of the discharge modes.

The gas-solids flow patterns in dipleg are usually defined by the analysis of flow parameters (axial distributions of the pressure, particle velocity, or concentration) (Geldart et al. 1993; Gil et al. 2002), which are mainly affected by operating conditions (solids flux and negative pressure), physical properties of particles (particle density, particle size distribution, etc.), and geometric structure of dipleg (Smolders and Baeyens 1995; Wang et al. 2000a, b; Geldart and Radtke 1986; Knowlton et al. 1986). These flow parameters have the characteristics of dynamic change, which may be attributed to the gas pulsation, the particle agglomeration and dispersion, the vortex generation and shedding, the bubble formation and eruption, the expansion and compression of gas flow impacted by particles, and the friction between particles and bed wall (Bi 2007; Punčochár and Drahoš 2005; van der Schaaf et al. 1998; Fan et al. 1981).

Comparatively speaking, the nonintrusive measurement of pressure fluctuation is much easier than the intrusive measurement of particle velocity and concentration. And the pressure fluctuation signal data contain sufficient fluidization information implied in gas-solids two-phase flow. So, the measurement of pressure fluctuation has been widely used in many studies of gas-solids fluidization. And several types of data processing methods have been applied to analyze the pressure fluctuation in gas-solids two-phase flow, such as the statistical methods (standard deviation, probability density function, etc.) based on time domain (Yang and Leu 2008; van Ommen et al. 2011; Lin et al. 2001) and the Fourier transform methods (power spectrum density, coherence function, etc.) based on frequency domain (Fan et al. 1981; van der Schaaf et al. 1999; Kage et al. 2000; Shou and Leu 2005). The characteristic values of the pressure fluctuation can be extracted by using these signal data processing methods, explaining the fluctuation mechanism of gas-solids 
two-phase flow in the diplegs. The operation of diplegtrickle valve has the characteristics of dynamic change of flow parameters because the slugs of solids flow out of the dipleg and slugs of gas back up into the trickle valve (Sinclair et al. 1983). But the previous literature reports mainly focused on the static analysis of statistical mean values of pressure data and less on the dynamic change analysis.

Therefore, in this work, an experimental apparatus of the dipleg-trickle valve system was established to simulate the operation of the suspended secondary cyclone dipleg-trickle valve in FCC disengager, which usually operates at a relatively lower solids flux and a higher negative pressure. The transient pressure fluctuation at different axial positions of the whole dipleg-trickle valve system was measured by pressure transducer under the wide operating conditions (solids flux and negative pressure). The flow regimes in the dipleg and the discharge modes in the trickle valve were identified by combining the experimental phenomena with the analysis of transient pressure fluctuation by using the data processing methods. The mechanism about the origin and propagation of pressure fluctuation in the system was also further discussed based on a dynamic analysis.

\section{Experiments}

\subsection{Experimental apparatus}

Figures 2 and 3 show the schematic diagram and the photographs of the experimental apparatus, respectively. In

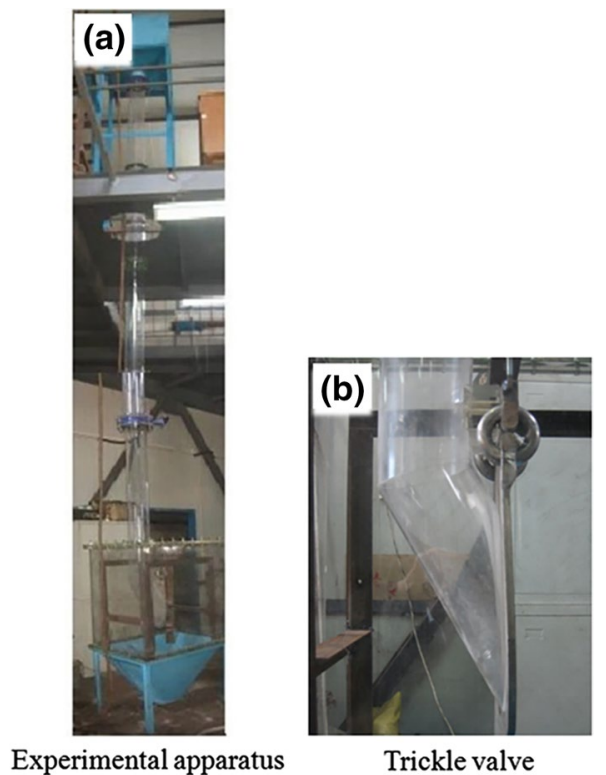

Fig. 3 Photographs of experimental apparatus

order to clearly observe the experimental phenomena of trickle valve, a batch solids transfer system was used in the experiment, which could operate continuously for a certain length of time. The experimental apparatus was mainly composed of a top hopper, a dipleg, a trickle valve, and a bottom rectangular collector for particles. The dipleg had an inner diameter of $150 \mathrm{~mm}$ and a height of $5000 \mathrm{~mm}$. The trickle valve with a nominal diameter of DN $150 \mathrm{~mm}$ was

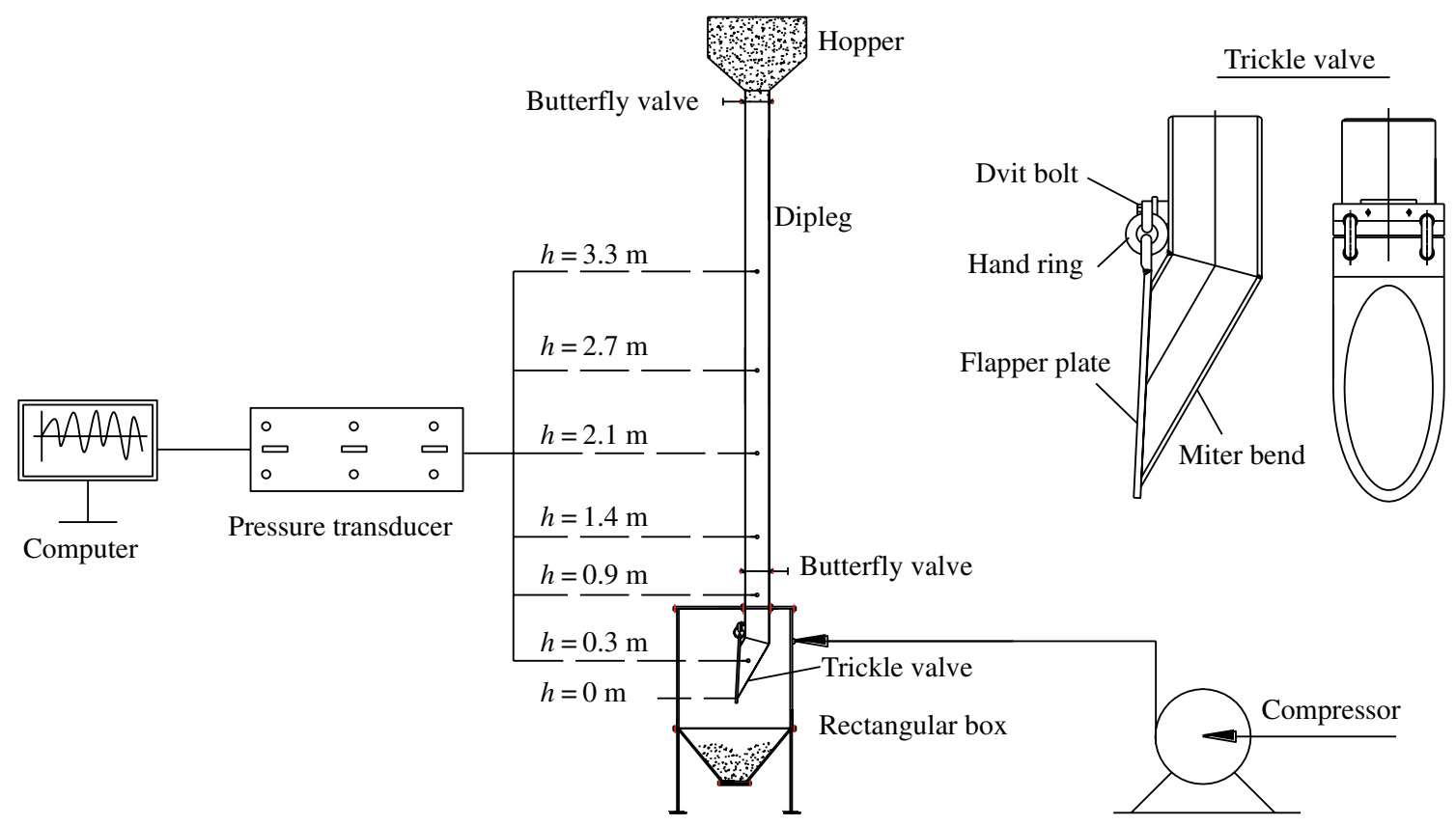

Fig. 2 Schematic diagram of experimental apparatus 
connected with the bottom end of the dipleg and suspended in the rectangular collector, simulating the case of FCC secondary cyclone dipleg-trickle valve system. The trickle valve was mainly composed of a short inclined pipe (or called as the miter bend) and a flapper plate. The top section of flapper plate was connected with the inclined pipe by two rotatable hand rings and two davit bolts as shown in Figs. 2 and 3. The flapper plate can rotate flexibly back and forth around the two-hand rings. The installation angle between the flapper plate and the vertical line at the trickle valve exit was $5^{\circ}$ for generating the natural closure force. In order to simulate the operation of industrial trickle valve, the weight and the size of the flapper plate employed in the experiment were same as the industrial flapper plate. For clearly observation of experimental phenomena, the dipleg, the rectangular collector, and the inclined pipe of trickle valve were made of transparent plexiglas. And the other parts of the experimental apparatus including the flapper plate were made of carbon steel.

The solid particles employed in the experiment was the equilibrium FCC catalyst with a Sauter mean diameter of $67 \mu \mathrm{m}$, a particle density of $1500 \mathrm{~kg} / \mathrm{m}^{3}$, and a bulk density of $940 \mathrm{~kg} / \mathrm{m}^{3}$. The particle size distribution of FCC catalysts is displayed in Fig. 4.

In order to simulate the work environment with negative pressure gradient for particle conveying and discharging operation along the dipleg-trickle valve system in FCC disengager, the pressurized air from a compressor was introduced into the rectangular collector to keep a certain operation pressure and form the negative pressure gradient (or pressure difference) between inside and outside of the dipleg-trickle valve system during the experiments. The pressure in the space of rectangular collector was measured by a U-tube manometer. First, the catalyst particles were fed into the top hopper and then flowed down the dipleg and fell into the rectangular collector through the trickle valve. The solids

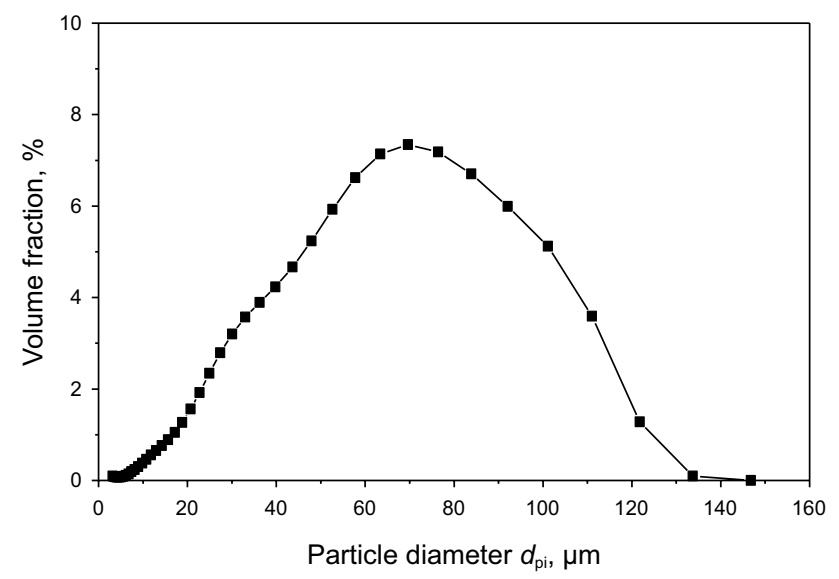

Fig. 4 Particle size distribution of FCC catalysts flux in the dipleg was controlled by a butterfly valve under the hopper. The solids flux was determined by simultaneously measuring the accumulating height in the dipleg and the falling time of catalyst particles when closing the butterfly valve installed at the bottom section of the dipleg. In these experiments, the solids flux was varied within $50.0 \mathrm{~kg} /$ $\left(\mathrm{m}^{2} \mathrm{~s}\right)$ based on the cross-sectional area of the dipleg, and the operation range of negative pressure (or pressure difference) between inside and outside of the dipleg-trickle valve system was within $11.0 \mathrm{kPa}$.

In the experiments, six pressure taps along the axial direction of dipleg were arrayed based on the zero height at the exit bottom of trickle valve, namely $0.3 \mathrm{~m}, 0.9 \mathrm{~m}, 1.4 \mathrm{~m}, 2.1 \mathrm{~m}$, $2.7 \mathrm{~m}, 3.3 \mathrm{~m}$, as shown in Fig. 2. The transient pressure fluctuation at each tap was measured by pressure transducer. The sampling frequency of pressure transducer was $333 \mathrm{~Hz}$, and the maximum sampling time was $180 \mathrm{~s}$. The transient pressure fluctuation signals in the six measuring levels were collected simultaneously in the experiments, and the experimental phenomena were also recorded by a digital camera to monitor the flow regimes and discharge modes in the dipleg-trickle valve system.

\subsection{Data processing method}

\subsubsection{Power spectrum density analysis}

The power spectrum density (PSD) is a method to analyze the energy content of a signal associated with to the frequencies of a physical phenomenon. The power spectrum density function, $P_{x x}$, of a time series signal, $x(t)$, is the Fourier transform of its autocorrelation function, $R_{x x}$, as written by Eqs. (1) and (2). The function expresses the behavior of a signal in frequency domain rather than in time domain (Fan et al. 1981; van der Schaaf et al. 1999; Kage et al. 2000; Shou and Leu 2005). In the PSD analysis of pressure fluctuation, the frequency corresponding to the maximum energy of transient pressure fluctuation signal is called as the dominant frequency, which reflects the overall pulsation frequency of gas-solids two-phase flow. So, the PSD analysis of signal can extract the peculiar information reflecting the gas-solids flow behavior in frequency domain.

$$
\begin{aligned}
& P_{x x}(f)=\int_{-\infty}^{+\infty} R_{x x}(\tau) \mathrm{e}^{(-i 2 \pi f \tau)} \mathrm{d} \tau \\
& R_{x x}(\tau)=\lim _{T \rightarrow \infty} \frac{1}{T} \int_{-T / 2}^{+T / 2} x(t) x(t+\tau) \mathrm{d} t
\end{aligned}
$$




\subsubsection{Coherence analysis}

The coherence analysis has been used to measure the similarity of two signals at a frequency $f$ (Cai et al. 1990). The coherence coefficient $\gamma_{x y}^{2}(f)$ can be defined as follows.

$\gamma_{x y}^{2}(f)=\frac{\left|P_{x y}(f)\right|^{2}}{P_{x x}(f) P_{y y}(f)}$

where $P_{x x}(f)$ and $P_{y y}(f)$ are the auto-power spectrum of signals $P_{x}(t)$ and $P_{y}(t)$, respectively. $P_{x y}(f)$ is the cross-power spectrum of signals $P_{x}(t)$ and $P_{y}(t) . P_{x x}(f), P_{y y}(f)$, and $P_{x y}(f)$ are defined as follows.

$P_{x x}(f)=\frac{2}{T}\left|P_{x}(f)\right|^{2}=\frac{2}{T} P_{x}^{*}(f) P_{x}(f)$

$P_{y y}(f)=\frac{2}{T}\left|P_{y}(f)\right|^{2}=\frac{2}{T} P_{y}^{*}(f) P_{y}(f)$

$P_{x y}(f)=\frac{2}{T} P_{x}(f) P_{y}(f)$

where $P_{x}^{*}(f)$ and $P_{y}^{*}(f)$ are the conjugate complex of $P_{x}(f)$ and $P_{y}(f) . P_{x}(f)$ and $P_{y}(f)$ are obtained from the Fourier transformation of signals $P_{x}(t)$ and $P_{y}(t)$ over the sampling time interval, $T$, expressed by the following Eqs. (7) and (8).

$P_{x}(f)=\int_{0}^{T} P_{x}(t) \mathrm{e}^{-j 2 \pi f t} \mathrm{~d} t$

$P_{y}(f)=\int_{0}^{T} P_{y}(t) \mathrm{e}^{-j 2 \pi f t} \mathrm{~d} t$

In Eq. (3), the coherence coefficient, $\gamma_{x y}^{2}(f)$, ranges from 0 to 1 , corresponding to fully uncorrelated and fully correlated time series at frequency $f$, respectively. In this work, the coherence coefficient, $\gamma_{x y}^{2}(f)$, has been used to discern the different sources and propagation of pressure fluctuations in the dipleg-trickle valve system.

\section{Results and discussion}

\subsection{Experimental phenomena}

\subsubsection{Flow regimes in the dipleg}

During the experiments, the flow phenomena in the dipleg were recorded by a digital camera. The flow regimes based on the experimental phenomena in the dipleg can be divided into two patterns, namely the dilute-dense phase coexisting falling flow and the dilute falling flow, as shown in Fig. 5, which depends on the solids flux and the negative pressure.

At a given negative pressure, when the solids flux is relatively lower, the dilute-dense phase coexisting falling flow appears in the dipleg, as shown in Fig. 5a. There exists a certain height of dense phase in the bottom of the dipleg, and a dilute phase falling flow locates at the section between the inlet of dipleg and the surface of dense phase bed. As the top inlet of the dipleg employed in this work is not connected with a cyclone, but a hopper, there is no swirling flow in the upper dilute phase falling flow region of the dipleg. In the dilute phase falling flow region, the particles flow downward like rain. However, in the bottom dense phase flow region, the particles move downward at a low velocity. There are some bubbles rising in the dense phase flow, which are produced by gas from the rectangular collector through the exit of trickle valve. So the particle phase moves downward and gas phase moves upward in the dense phase flow region, which causes this region resembling a bubbling fluidized bed. The interface between the dilute falling flow and the dense flow moves up and down unsteadily. The dense phase bed in the bottom section of dipleg has the sealing effect

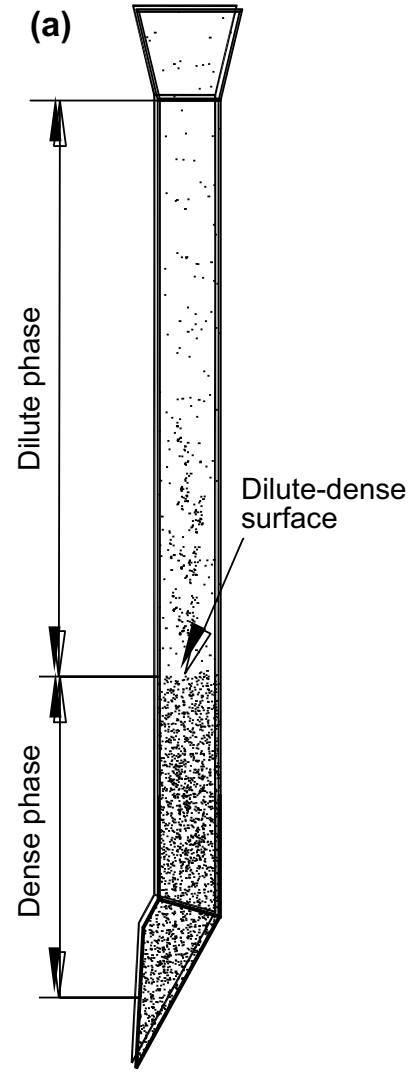

The dilute-dense phase coexisting falling flow

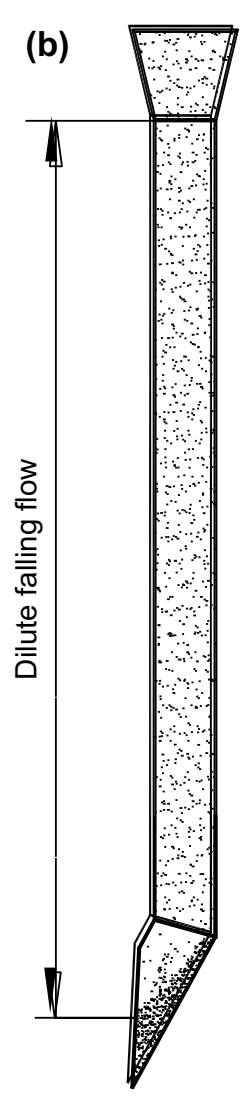

The dilute falling flow
Fig. 5 Diagram of flow regimes in the dipleg 
preventing the bypass of large quantity of gas outside of the dipleg. Therefore, the height of the dense phase bed is called as the sealing height of dipleg.

The experimental phenomena show that when the negative pressure is relatively lower, the sealing height will conversely decrease with increasing the solids flux, and the flow regime becomes the dilute falling flow as shown in Fig. 5 b. Due to the relatively higher downward particle velocity at the low solids flux, the dilute flow will occur unlike the dense conveying flow reported by Wei et al. (2016) for primary cyclone dipleg with high solids flux. However, at a given solids flux, the increases in negative pressure will increase the sealing height, inducing the regime transition from the dilute falling flow to the dilute-dense phase coexisting falling flow in the dipleg. Therefore, depending on the operating conditions, the two flow regimes in the dipleg can transform from each other.

\subsubsection{Discharge modes in the trickle valve}

Corresponding to the flow regimes in the dipleg, the trickle valve has two discharge modes in the operation process, namely an intermittent periodic dumping discharge and a continuous trickling discharge, as shown in Fig. 6.

At a certain solids flux and negative pressure, if the flow regime in the dipleg is in the status of dilute-dense phase coexisting falling flow, the trickle valve will work as the mode of intermittent periodic dumping discharge. When the dense phase bed in the dipleg reaches to a certain height with an enough static pressure head to overcome the force produced by the pressure impacting on the outside surface of the flapper plate, the flapper plate will open abruptly from a close status to a large opening one, slapping the exit of trickle valve intensively. The particles accumulated in the dipleg are discharged as a dumping way in a short time, as shown in Fig. 6a. Meanwhile, the gas leakage occurs along the upper semi-circumference of the exit, which flows from the space of rectangular collector into the trickle valve. The particles pass through the inclined pipe of trickle valve as
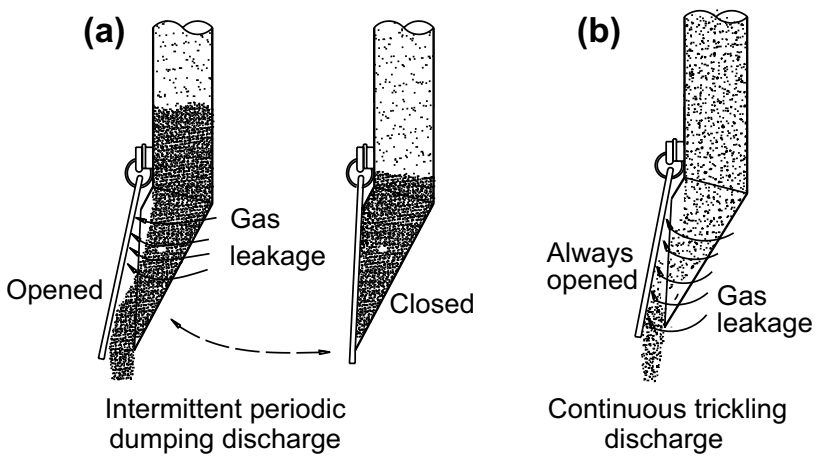

Fig. 6 Diagrams of discharge modes of trickle valve a stratified flow, as shown as the collection of photographs in Fig. 7.

The gas flows into the dipleg to form as the bubbles, which makes the dense bed have properties of a bubbling fluidized bed. The surface of the dense bed fluctuates up and down intensively. The static pressure head of the dense bed is also gradually decreased at the same time. At that moment, the static pressure head of the dense bed cannot counteract the force impacting on the outside surface of the flapper plate, and the flapper plate will close. The discharge process is completed in one time. Then, the particles start to accumulate in the dipleg again to form the dense height as before. The trickle valve will discharge particles in the next cycle time. Therefore, the trickle valve runs as a mode of intermittent periodic dumping discharge. Generally, this type of discharge is corresponding to the operating conditions with relatively higher negative pressure and lower solids flux, as well as to the dilute-dense phase coexisting falling flow regime in the dipleg.

When the negative pressure is relatively lower and the solids flux is relatively higher, the trickle valve will operate as a mode of continuous trickling discharge as shown in Fig. 6b, which is closely related to the dilute falling flow regime in the dipleg. For the flow regime as mentioned above, the conveying particles with a relatively higher velocity impact on the inside surface of the flapper plate, generating enough driving force to balance the resistant force impacting on the outside surface of the flapper plate. Then, the flapper plate keeps open to discharge particles as a continuous and trickling flow mode. In the process of discharge, the flapper plate always keeps open with a slight swing back and forth if the operating conditions are not changed. The maximum opening angle of the flapper plate is about $7^{\circ}$ in this case as observed in the experiments, which is slightly larger than the installation angle of $5^{\circ}$ of the flapper plate. As the particle flow rate in the continuous trickling discharge is very low, the gas from the space of the rectangular collector can leak into the trickle valve around the almost entire exit circumference of trickle valve, which also results in a stratified flow of particles in the inclined pipe of trickle valve.

\subsection{Pressure fluctuation in the dipleg-trickle valve system}

\subsubsection{Time mean pressure profiles}

Figure 8 displays the time mean pressure profiles in the dipleg for different flow regimes. At a given negative pressure (7 $\mathrm{kPa}$ as shown in Fig. 8), when the solids flux is gradually increased, the distributions of the time mean pressure clearly vary from the non-uniformity to the uniformity along the axial direction of dipleg, which 

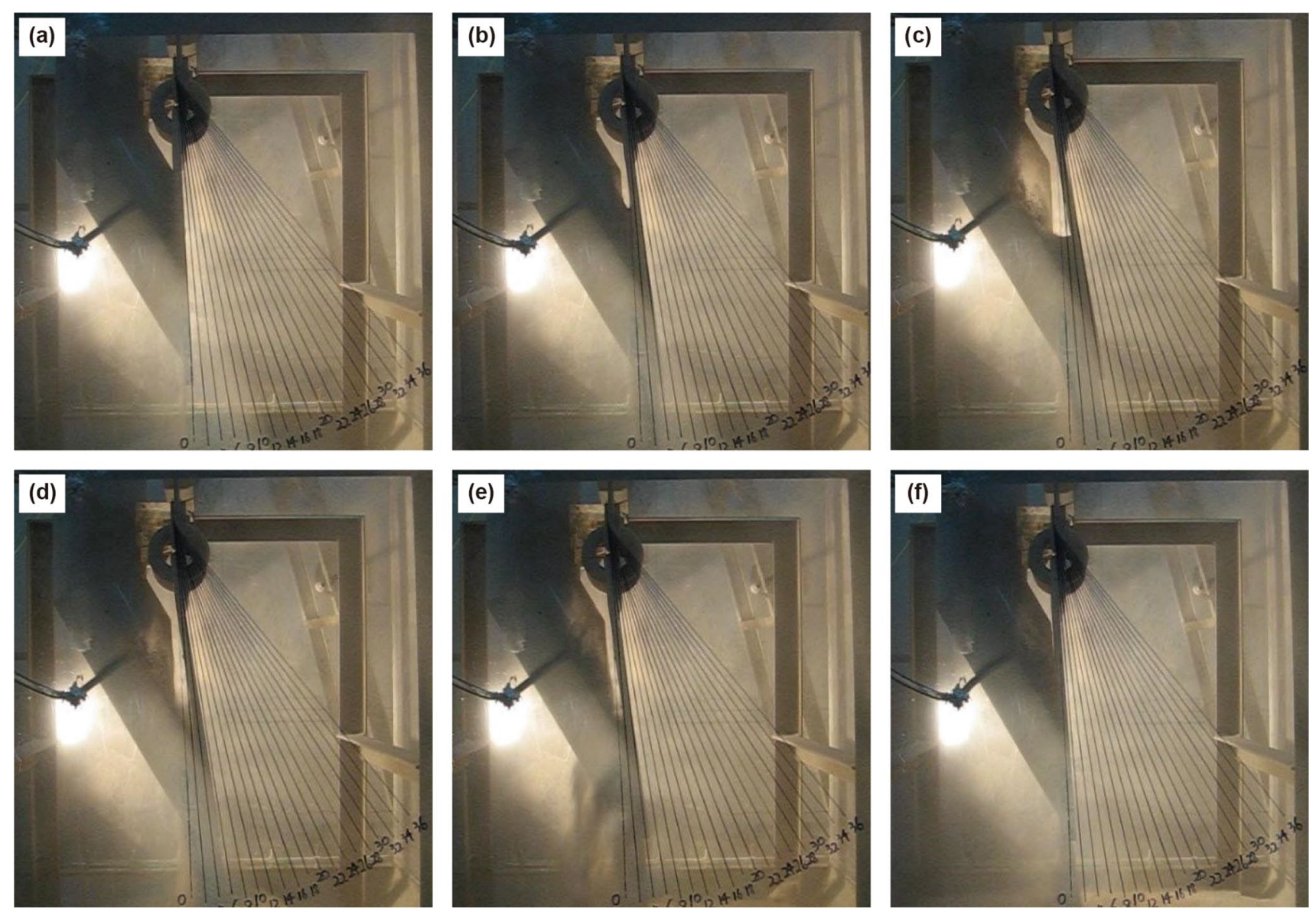

Fig. 7 Photographs of intermittent periodic dumping discharge of trickle valve at different time in a discharge cycle

demonstrates that the flow regime in the dipleg transforms from the dilute-dense phase coexisting falling flow to the dilute falling flow.

When the solids flux is relatively lower, the axial distribution of the time mean pressure appears an obvious inflection point, as shown in Fig. 8a, b. Above the critical height corresponding to the inflection point (or the dilute-dense surface), the distribution of time mean pressure is very uniform in the dilute phase flow. However, below the critical height (or in the dense phase bed), the time mean pressure is increased gradually with the axial position in close to the bottom of the dipleg. This also means that the concentration above the critical height is much lower than the one below the critical height, indicating that the dilute-dense phase coexisting falling flow occurs in the dipleg.

Figure $8 \mathrm{c}, \mathrm{d}$ shows that, when the solids flux increases, the axial distribution of time mean pressure becomes relatively more uniform along the dipleg except a slightly higher in the bottom region in close to the exit of trickle valve, due to the resistance of trickle valve. This type of axial distribution of time mean pressure or the axial distribution of particle concentration corresponds to the dilute falling flow.

\subsubsection{Transient pressure fluctuation profiles}

The flow behavior of solids in the dipleg-trickle valve system is a dynamic process, which can be described by pressure fluctuation parameter. Figure 9 displays the typical transient pressure fluctuation profiles in the dipleg under different operating conditions. It can be found that the pressure fluctuation profiles, especially in close to the exit of trickle valve, have significant difference under different operating conditions, which can be used to identify the two flow regimes and discharge modes in the dipleg-trickle valve system as mentioned above.

In Fig. 9a, the pressure fluctuation profiles in close to the exit of trickle valve are composed of zigzag peaks with low frequency and high amplitude, such as for the axial level of $0.3 \mathrm{~m}$ and $0.9 \mathrm{~m}$. In the other axial positions far from the exit of the trickle valve (from 1.4 to $3.3 \mathrm{~m}$ ), the pressure fluctuation profiles change gently with high frequency and low amplitude. The higher the axial position, the lower the pressure.

The pressure fluctuation profiles in Fig. 9a are corresponding to the dilute-dense phase coexisting falling flow 

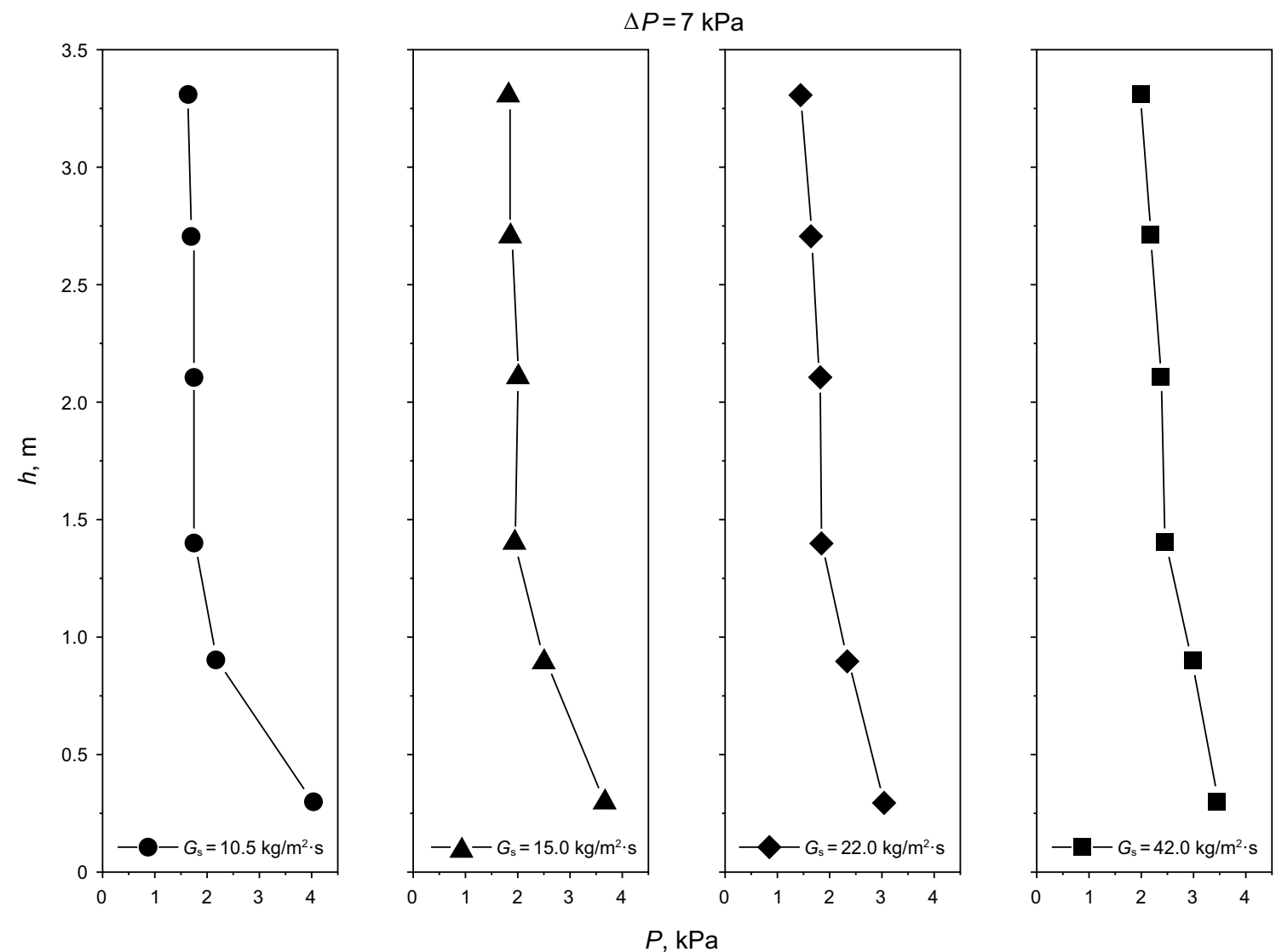

Fig. 8 Time mean pressure profiles for different flow regimes in the dipleg

regime for the dipleg and the intermittent periodic dumping discharge mode for the trickle valve. For the pressure fluctuation profiles at the axial level in closest to the exit of the trickle valve $(h=0.3 \mathrm{~m})$, the gradual ascending part of the zigzag peak with time means the accumulating process of particles in the dipleg when the flapper plate is in a closed state. The static pressure head keeps increasing up to a wave peak due to the formation of a dense bed with a certain height. And then, at the wave peak, the force impacting on the inside surface of flapper plate can balance the resultant force acting on the outside surface of flapper plate. The flapper plate starts to open and discharge particles, decreasing the dense bed level and the static pressure head, which is reflected by the descending part of the zigzag peak profile. It can be found that one-time discharge cycle is about $50 \mathrm{~s}$ for the operating condition in Fig. 9a. Therefore, the zigzag peak of pressure fluctuation located at the position in closest to the exit of trickle valve can be employed to identify the dilute-dense phase coexisting falling flow regime and the intermittent periodic dumping discharge in the dipleg-trickle valve system.

Figure $9 \mathrm{~b}$ gives the pressure fluctuations corresponding to the dilute falling flow regime for the dipleg and the continuous trickling discharge mode for the trickle valve. It shows that the transient pressure profile at each axial level has the similarity basically with high frequency and low amplitude due to the stable discharge of particles in this case. However, due to the slight swing back and forth for the flapper plate, the fluctuation extent of pressure profiles at the axial levels $(h=0.3 \mathrm{~m}, 0.9 \mathrm{~m}, 1.4 \mathrm{~m})$ in close to the exit of trickle valve is slightly higher than those at other levels ( $h=2.1 \mathrm{~m}, 2.7 \mathrm{~m}, 3.3 \mathrm{~m})$, but obviously distinguish from those in the dilute-dense phase coexisting falling flow regime and the intermittent periodic dumping discharge mode.

\subsubsection{Effect of operating conditions on pressure fluctuation}

In the experiments, it can be found that the operating condition has the obvious effects on the flow regime and the discharge mode in the dipleg-trickle valve system. Figure 10 displays the effects of the solids flux and the negative pressure on the pressure fluctuation profiles at the location $(h=0.3 \mathrm{~m})$ in closest to the exit of trickle valve.

As shown in Fig. 10a, at a given solids flux $\left(G_{\mathrm{s}}=17.4 \mathrm{~kg} /\right.$ $\left(\mathrm{m}^{2} \mathrm{~s}\right)$ ), when the negative pressure is decreased from 5.1 

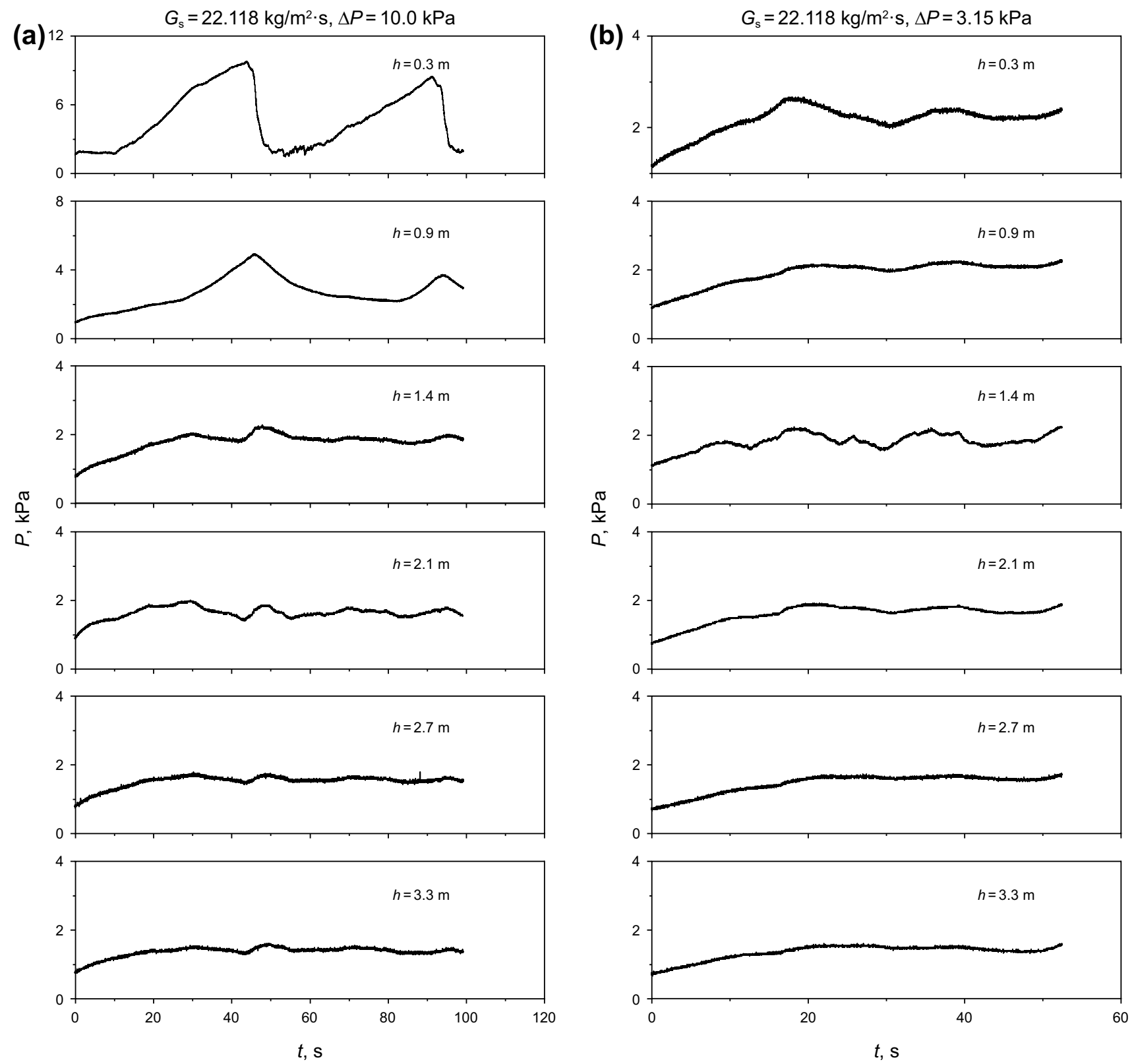

Fig. 9 Typical transient pressure fluctuation profiles for different flow regime and discharge mode in the dipleg-trickle valve system

to $2.1 \mathrm{kPa}$, the pressure profiles gradually change from the zigzag peaks with low frequency and high amplitude into the smooth fluctuations with high frequency and low amplitude. This clearly indicates that the flow regime and the discharge mode are also changed, respectively, transforming from the dilute-dense phase coexisting falling flow into the dilute falling flow regime for the dipleg and from the intermittent periodic dumping discharge into the continuous trickling discharge mode for the trickle valve.

On the contrary, as shown in Fig. 10b, at a given negative pressure $(\Delta P=7.05 \mathrm{kPa})$, decreasing the solids flux from 42.0 to $10.5 \mathrm{~kg} /\left(\mathrm{m}^{2} \mathrm{~s}\right)$ will also change the pressure profiles from the smooth fluctuations into the zigzag peaks. In this case, the dilute falling flow will evolve into the dilute-dense phase coexisting falling flow regime for the dipleg. Meanwhile, the continuous trickling discharge will transform into the intermittent periodic dumping discharge mode for the trickle valve.

\subsection{Power spectrum density of pressure fluctuation}

The time series of pressure signals can be processed by using the Fourier transform method in frequency domain to obtain the power spectrum density (PSD), which is used to 

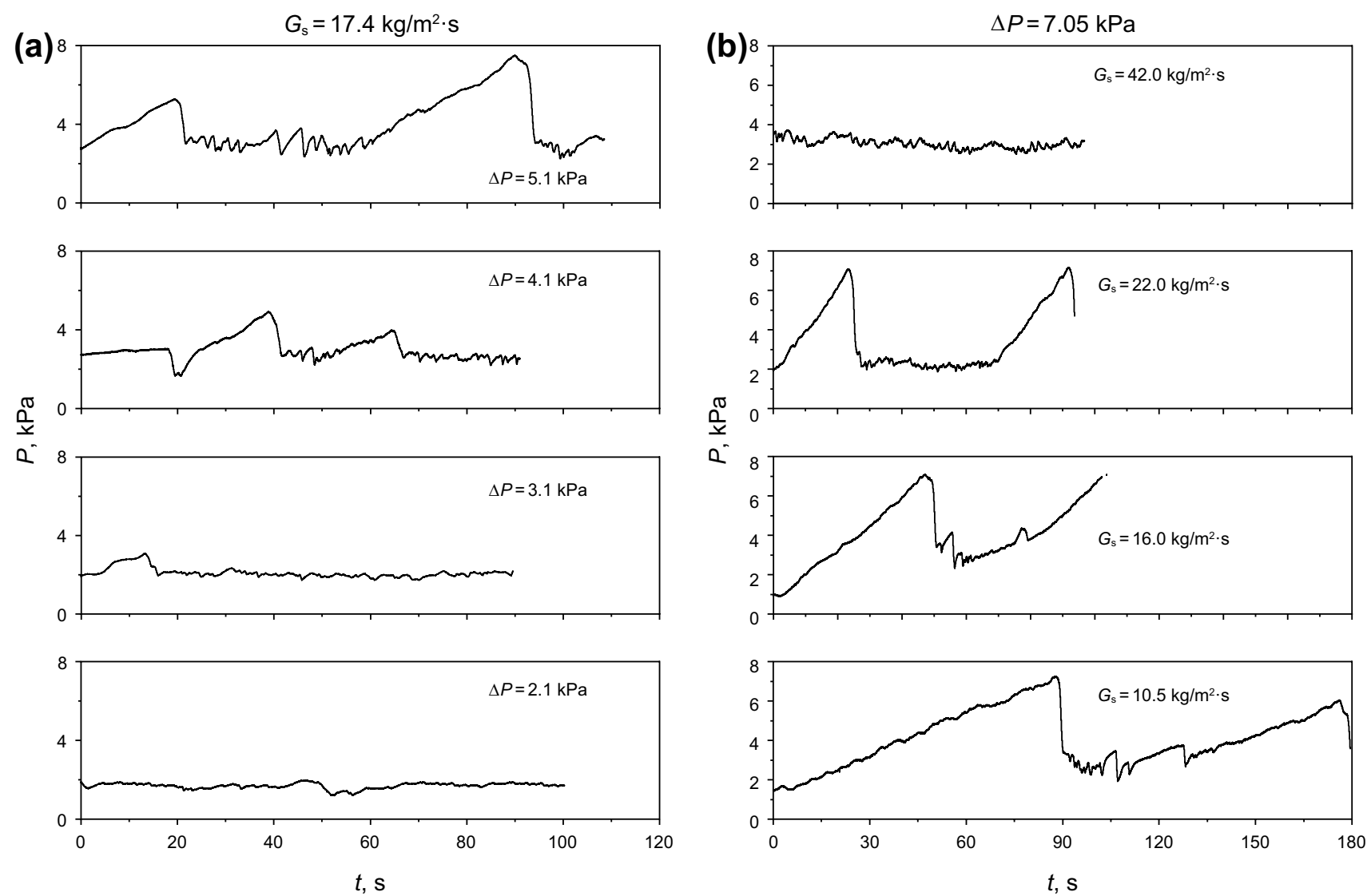

Fig. 10 Effects of operating conditions on pressure fluctuation $(h=0.3 \mathrm{~m})$

extract the dominant frequency of pressure fluctuation signals, reflecting the dynamic feature of pressure fluctuation.

Figure 11 shows the PSD profile of the transient pressure fluctuation at each axial level of the dipleg under different operating conditions. Figure 11a displays the PSD profiles for the dilute-dense phase coexisting falling flow regime and the intermittent periodic dumping discharge mode. Figure $11 \mathrm{~b}$ shows the PSD profiles corresponding to the dilute
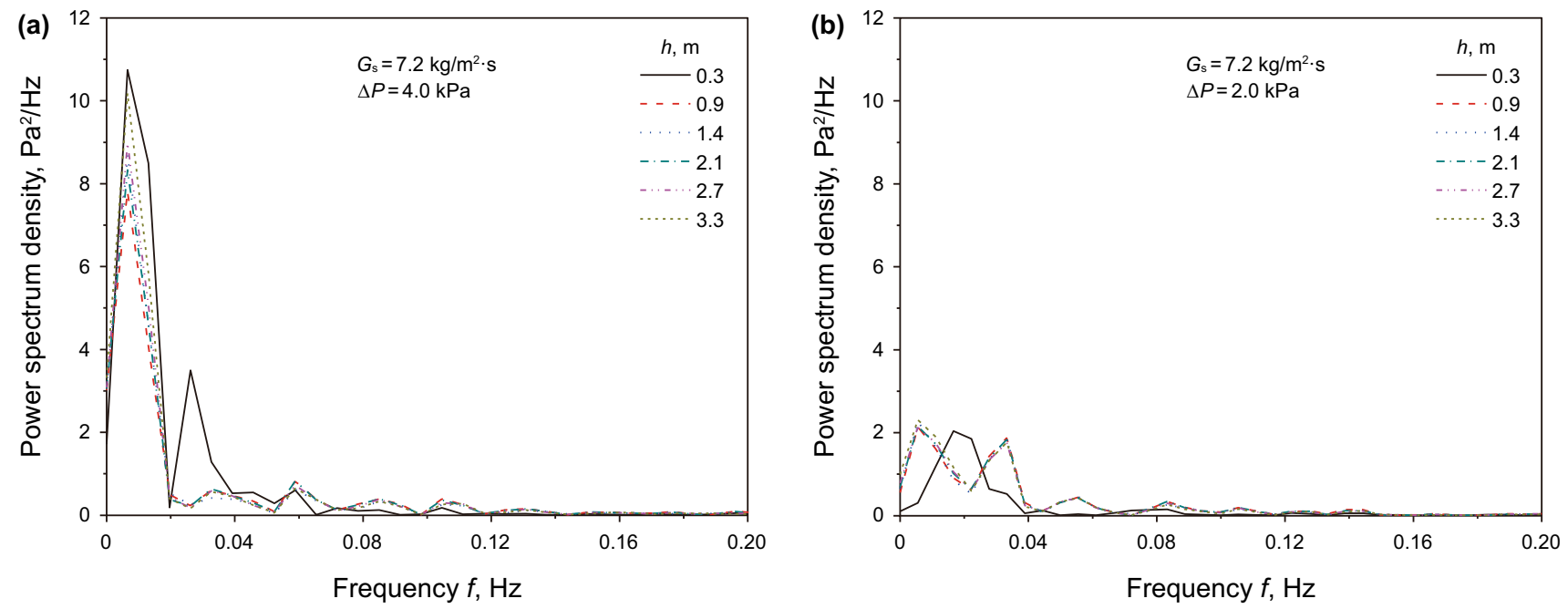

Fig. 11 Power spectrum density profiles of pressure fluctuations in the dipleg 
falling flow regime and the continuous trickling discharge mode.

The dominant frequency of pressure signals is closely related to the flow regime and the discharge mode. Figure 11a shows that the PSD profiles have a similarity and an obvious wave crest with a dominant frequency of about $0.01 \mathrm{~Hz}$. The power energy corresponding to the dominant frequency at the axial position $(h=0.3 \mathrm{~m})$ in closest to the exit of trickle valve is relatively higher than that at other axial positions. However, in Fig. 11b, each of the PSD profiles has a dominant frequency of about $0.03 \mathrm{~Hz}$ and several sub-frequencies. All the PSD profiles overlap well from each other, indicating the consistency of pressure fluctuation propagation in the dipleg.

Comparing Fig. 11a with b, it can be found that the power energy corresponding to the dominant frequency in the intermittent periodic dumping discharge mode (and the dilute-dense phase coexisting falling flow regime) is much higher than that in the continuous trickling discharge (and the dilute falling flow regime). Therefore, the flow regimes and the discharge modes in the dipleg-trickle valve system can also be identified by using the PSD analysis of the transient pressure fluctuation.

\subsection{Coherence analysis of pressure fluctuation}

As mentioned above, the PSD analysis of the transient pressure fluctuation reflects the fluctuation power under a dominant frequency, discriminating the flow regimes and the discharge modes in the dipleg-trickle valve system. However, this method cannot determine the propagation direction of pressure fluctuation which is very important to explain the dynamic features of gas-solids flow in the system. In this work, the coherence function analysis method is used to determine the similarity or difference of pressure fluctuation signals between two measurement positions (as described in Sect. 2.2.2), so as to determine the propagation direction of pressure fluctuation. If the coefficient value of the coherence function is close to zero, this means that the pressure signal is damped markedly by some other sources from one measurement position to another one. On the other hand, the situation is opposite if the value is close to 1 , which proves that the propagation is well-transported and attenuation of the pressure wave is not evident. Generally, when the value of the coherence coefficient is above 0.6 , it is considered to be similar for two objective signals.

In this section, the axial distribution of the coherence coefficient is used to explain the propagation of pressure wave under the different flow regimes and discharge modes in the dipleg-trickle valve system. The maximum values of coherence coefficients for each of two group adjacent pressure fluctuation signals along axial positions are displayed in Fig. 12. It is shown that, at a given solids flux [Fig. 12a, $\left.G_{\mathrm{s}}=17.4 \mathrm{~kg} /\left(\mathrm{m}^{2} \mathrm{~s}\right)\right]$, the increases in negative pressure will change the axial distribution of coherence coefficient from a uniformity distribution to a sudden change at an axial
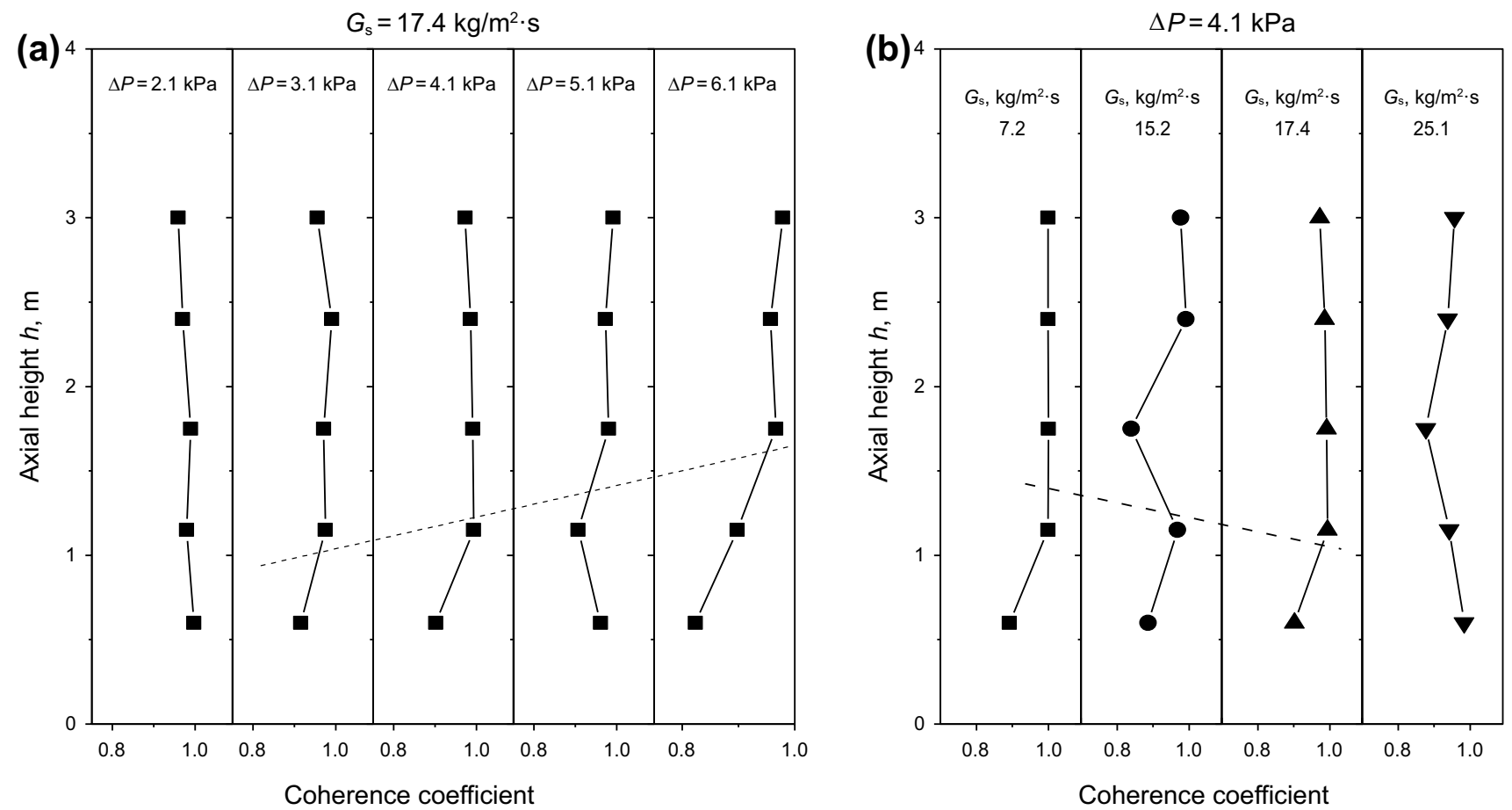

Fig. 12 Distribution of coherence coefficient of pressure fluctuation between two adjacent positions along the axial height of dipleg 
position. Similarly, as shown in Fig. 12b, at a given negative pressure $(\Delta P=4.1 \mathrm{kPa})$, the decreases in solids flux will induce the same change tendency as shown in Fig. 12a. As mentioned above, the change of the operating conditions will induce the transition of flow regimes and discharge modes in the dipleg-trickle valve system, which contributes to the different axial distribution of the coherence coefficient.

In Fig. 12a, b, the case for axial uniform distribution of coherence coefficient is corresponding to the dilute falling flow regime in the dipleg and the continuous trickling discharge mode for the trickle valve. It demonstrates that the pressure fluctuation signal has well consistency from the top to the bottom in the whole dipleg-trickle valve system, which has the unattenuated feature of downward propagation of pressure fluctuation similarly originated from the top in fluidized beds as reported by $\mathrm{Bi}(2007)$, Punčochár and Drahoš (2005), van der Schaaf et al. (1998) and Fan et al. (1981). That is to say, the source of pressure fluctuation originates from the feed at the top inlet of the dipleg and propagates downward to the bottom exit for this case. The down-flowing particles look like a rain falling inside the dipleg. The gas-solids flow in the dipleg is flowing against negative pressure, and the slip velocity is upward for balancing the negative pressure gradient, which results in compressing the gas flowing up the dipleg. The gas is compressed and expanded alternately to induce the non-uniform distribution of the particle concentration and the pressure. Therefore, the pressure fluctuation is attributed to the unstable feed and the compressed gas for this case.

However, the sudden change of coherence coefficient at an axial position as shown in Fig. 12a, b demonstrates that the pressure fluctuation signal has well consistency only in the upper section or in the bottom section, respectively. This type of axial distribution of coherence coefficient is closely related to the dilute-dense phase coexisting falling flow regime in the dipleg and the intermittent periodic dumping discharge mode for the trickle valve. The axial uniform distribution of coherence coefficient in the upper section is corresponding to the dilute phase falling flow. The propagation of pressure fluctuation originates from the feed at the top inlet and propagates downward along the dipleg. The falling particle clusters interact with the up flowing gas, causing the fluctuation of pressure in this section. Meanwhile, the consistency between two adjacent pressure signals in the lower dense bed reveals that another pressure fluctuation propagates in this section. The pressure fluctuation mainly originates from the discharge oscillation at the bottom exit, and the bubble coalescence and splitting in the bubble passage, which propagates upward in the dense bed. The intermittent periodic dumping discharge mode causes the dynamic variation in pressure in this region. Meanwhile, the bubble eruption at the surface of the dense phase bed can cause a pressure fluctuation to propagate downward along the dense bed with no attenuation similar to that in fluidized beds reported by Bi (2007), Punčochár and Drahoš (2005), van der Schaaf et al. (1998) and Fan et al. (1981). So, four types of pressure fluctuation originating, respectively, from the top inlet feed, the bottom discharge oscillation, the rising bubble passage, and the bubble eruption at the bed surface, encounter at an axial position and interact from each other to attenuate individually, leading to the appearance of the transition point of coherence coefficient along the axial distribution.

Therefore, these distribution features of the coherence coefficient can also be used to demarcate the flow regimes and discharge modes and further to predict the origin and propagation of pressure fluctuation in the dipleg-trickle valve system as shown in Fig. 13. For the case of the intermittent periodic dumping discharge mode and the dilute-dense phase coexisting falling flow regime (Fig. 13a), the energy of global pressure fluctuation mainly originates from the bottom oscillation of particles dumping discharge through the trickle valve, the coalescence and splitting of rising bubble (or void) in passage in the lower dense bed section, the bubble eruption at the surface of the dense bed, the instable feed at the inlet of dipleg, and the compressed gas impacted by clusters in the upper dilute section. The pressure fluctuation from the discharge oscillation and bubble passage propagates upward in the lower dense bed section. And the pressure fluctuation from the instable feed at the dipleg inlet and the compressed gas in the upper dilute section propagates downward. (a)

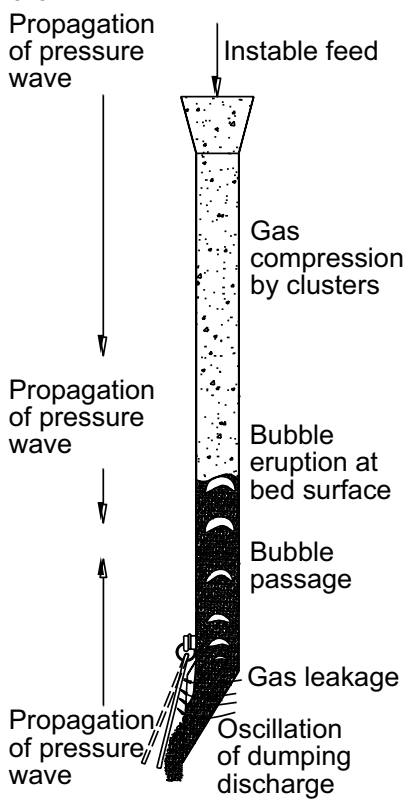

(b)

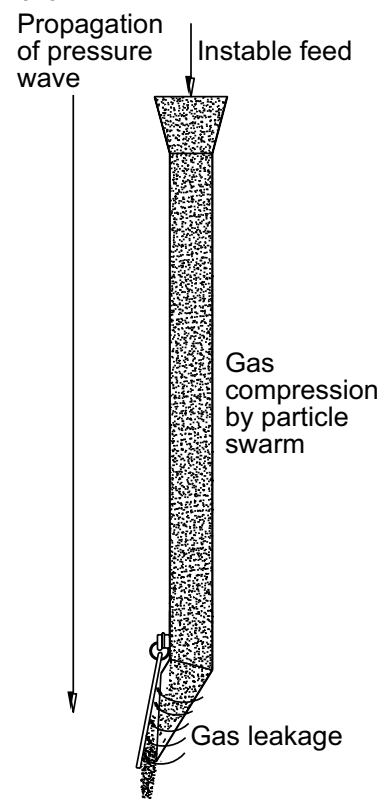

Fig. 13 Diagram showing the origin and propagation direction of pressure fluctuation (or pressure wave) in the dipleg-trickle valve system 
However, for the continuous trickling discharge mode and the dilute falling flow regime (Fig. 13b), due to the continuous and steady discharge of trickle valve, the oscillation produced by this type of discharge is relatively weak. The energy of global pressure fluctuation for this case mainly originates from the upper instable feed at the inlet of dipleg and from the compressed gas impacted by the dilute falling particle swarms in the dipleg. The pressure fluctuation propagates downward along the dipleg.

\subsection{Flow regime and discharge mode map}

Based on the experimental phenomena and the data analysis as mentioned above, the operation of the experimental dipleg-trickle valve system can be divided into two types of discharge modes and flow regimes, which are closely related to the operating parameters, the solids flux $\left(G_{\mathrm{s}}\right)$, and the negative pressure $(\Delta P)$. So, in this work, a map describing the relationship between the operation modes of diplegtrickle valve system and the operating parameters is plotted in Fig. 14. The region above the demarcation line expresses the dilute-dense phase coexisting falling flow regime in the dipleg and the intermittent periodic dumping discharge mode in the trickle valve, respectively. Correspondingly, the region below the demarcation line represents the dilute falling flow regime and the continuous trickling discharge mode, respectively.

This map is suitable for predicting the operation status of a dipleg-trickle valve system at low solids flux and variable negative pressure, especially for the secondary suspended cyclone dipleg-trickle valve system in the FCC disengager which usually has a very low particle concentration at the secondary cyclone inlet. Therefore, as long as the operating parameters $\left(G_{\mathrm{s}}\right.$ and $\left.\Delta P\right)$ are known, the flow regimes and the discharge modes in the dipleg-trickle valve system could be

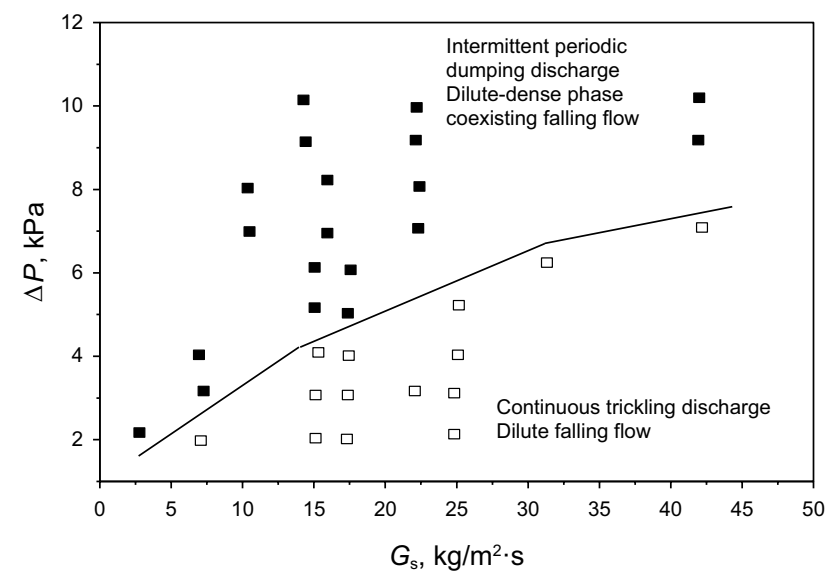

Fig. 14 Flow regime and discharge mode map in the dipleg-trickle valve system determined from the map, which can be applied to predict and monitor its operation status in the FCC disengager.

\section{Conclusions}

In this work, the flow regimes and discharge modes in the dipleg-trickle valve system were studied experimentally based on the measurement of transient pressure fluctuation. The experimental phenomena show that the flow regimes of particles down the dipleg could be divided into two types, the dilute-dense phase coexisting falling flow, and the dilute falling flow, which closely correlate with the operating parameters (solids flux and negative pressure). The change of operating parameters can cause the transformation of these two flow regimes from each other. Correspondingly, the trickle valve also has two discharge modes, the intermittent periodic dumping discharge, and the continuous trickling discharge. The former corresponds to the dilute-dense phase coexisting falling flow in the dipleg, and the latter corresponds to the dilute falling flow in the dipleg.

The profiles of transient pressure fluctuation in close to the exit of trickle valve can be used to demarcate the two flow regimes and discharge modes. The zigzag shape of transient pressure fluctuation represents the operation status with the dilute-dense phase coexisting falling flow regime in the dipleg and the intermittent periodic dumping discharge mode for the trickle valve. Meanwhile, the smooth transient pressure fluctuation describes the characteristics of the dilute falling flow in the dipleg and the continuous trickling discharge mode for the trickle valve.

The coherence coefficient based on frequency domain well explains the origin and propagation of pressure fluctuation in the dipleg-trickle valve system. The transient pressure fluctuation shows that there exists dynamic property of gas-solids flow in the dipleg-trickle valve system. The operating conditions have obvious effects on the pressure fluctuation. The power spectrum density (PSD) based on frequency domain shows that the dominant frequency of pressure fluctuation time series concentrates on the range of less than $0.03 \mathrm{~Hz}$. It means that the gas-solids flow in the dipleg-trickle valve system is characterized by the low frequency pulsation.

The bottom discharge oscillation, the coalescence and splitting of rising bubbles (or voids) in passage, the bubble eruption at the surface of dense phase bed, the instable feed at the inlet of dipleg, and the compressed gas impacted by clusters jointly contribute to the fluctuation of pressure in the dipleg-trickle valve system. The pressure fluctuation from the discharge oscillation and bubble passage propagates upward, and the one from the instable feed, the bubble eruption, and the compressed gas propagates downward in the dipleg-trickle valve system. 
Acknowledgements The authors acknowledge the supports by the National Natural Science Foundation of China (Grant Nos. 21776305 , 21978322), and the China Petrochemical Joint Foundation (Grant No. U1862202)

Open Access This article is licensed under a Creative Commons Attribution 4.0 International License, which permits use, sharing, adaptation, distribution and reproduction in any medium or format, as long as you give appropriate credit to the original author(s) and the source, provide a link to the Creative Commons licence, and indicate if changes were made. The images or other third party material in this article are included in the article's Creative Commons licence, unless indicated otherwise in a credit line to the material. If material is not included in the article's Creative Commons licence and your intended use is not permitted by statutory regulation or exceeds the permitted use, you will need to obtain permission directly from the copyright holder. To view a copy of this licence, visit http://creativecommons.org/licenses/by/4.0/.

\section{References}

Bi HT. A critical review of the complex pressure fluctuation phenomenon in gas-solids fluidized beds. Chem Eng Sci. 2007;62(13):3473-93. https://doi.org/10.1016/j.ces.2006.12.092.

Bouma JH. Particle recovery and dipleg flow in fluidized catalytic cracking. Dissertation, University of Twente. 1998; p. 7-8.

Bristow TC, Shingles T. Cyclone dipleg and trickle valve operation. In: Grace JR, Shemilt LW, Bergougnon MA, editors. Fluidization VI. New York: Engineering Foundation; 1989. p. 161-8.

Cai P, Jin Y, Yu ZQ, Wang ZW. Mechanism of flow regime transition from bubbling to turbulent fluidization. AIChE J. 1990;36(6):9556. https://doi.org/10.1002/aic.690360619.

Cortés C, Gil A. Modeling the gas and particle flow inside cyclone separators. Prog Energy Combust Sci. 2007;33:409-52. https:// doi.org/10.1016/j.pecs.2007.02.001.

Dries HWA, Bouma JH. Down flow of class-a powder in cyclone diplegs. In: Proceedings of the 5th international conference on circulating fluidized beds, Tsinghua University, Beijing, China. 1997; p. 585-90.

Fan LT, Ho T-C, Hiraoka S, Walawender WP. Pressure fluctuations in a fluidized bed. AIChE J. 1981;27(3):388-96. https://doi. org/10.1002/aic.690270308.

Geldart D, Radtke AL. The effect of particle properties on the behavior of equilibrium cracking catalysts in standpipe flow. Powder Technol. 1986;47(2):157-65. https://doi.org/10.1016/00325910(86)80112-7.

Geldart D, Broodryk N, Kerdoncuff A. Studies on the flow of solid down cyclonediplegs. Powder Technol. 1993;76(2):175-83. https ://doi.org/10.1016/S0032-5910(05)80025-7.

Gil A, Cortés C, Romeo LM, Velilla J. Gas-particle flow inside cyclone diplegs with pneumatic extraction. Powder Technol. 2002;128(1):78-91. https://doi.org/10.1016/S0032 $-5910(02) 00215-2$.

Hoffmann AC, Stein LE. Gas cyclones and swirl tubes principles, design and operation. Berlin: Springer; 2002. p. 235-56.

Jing S, Li HZ. Study on the flow of fine powders from hoppers connected to a moving-bed standpipe with negative pressure gradient. Powder Technol. 1999;101(3):266-78. https://doi.org/10.1016/ S0032-5910(98)00156-9.

Kage H, Agari M, Ogura H, Matsuno Y. Frequency analysis of pressure fluctuation in fluidized bed plenum and its confidence limit for detection of various modes of fluidization. Adv Powder Technol.
2000;11(4):459-75. https://doi.org/10.1163/156855200750172 060.

Knowlton TM, Mountziaris TJ, Jackson R. The effect of pipe length on the gravity flow of granular materials in vertical standpipes. Powder Technol. 1986;47(2):115-28. https://doi.org/10.1016/00325910(86)80107-3.

Leung LS, Jones PJ. Flow of gas-solid mixtures in standpipes: a review. Powder Technol. 1978;20(2):145-60. https://doi. org/10.1016/0032-5910(78)80044-8.

Leung LS, Wilson LA. Downflow of solids in standpipes. Powder Technol. 1973;7(6):343-9. https://doi.org/10.1016/00325910(73)80047-6.

Li HZ. Theory of nonfluidized gas solids flow and its application. China Part. 2005;3(1-2):27-39. https://doi.org/10.1016/S1672 -2515(07)60159-6.

Li YC, Lu YQ, Wang FM, Han K, Mi WS, Chen XH, et al.. Behavior of gas-solid flow in the downcomer of a circulating fluidized bed reactor with a V-valve. Powder Technol. 1997;91(1):11-6. https ://doi.org/10.1016/S0032-5910(96)03226-3.

Lin Q, Wei F, Jin Y. Transient density signal analysis and twophase microstructure flow in gas-solids fluidization. Chem Eng Sci. 2001;56(6):2179-89. https://doi.org/10.1016/S0009 $-2509(00) 00499-1$.

Mountziaris TJ, Jackson R. The effects of aeration on the gravity flow of particles and gas in vertical standpipes. Chem Eng Sci. 1991;46(2):381-407. https://doi.org/10.1016/00092509(91)80001-F.

Niccum PK. 20 questions: identify probable causes for high FCC catalyst loss. Hydrocarb Process. 2010;89:29-38.

Punčochár M, Drahoš J. Origin of pressure fluctuations in fluidized beds. Chem Eng Sci. 2005;60(5):1193-7. https://doi. org/10.1016/j.ces.2004.09.054.

Reddy Karri SB, Knowlton TM. Effect of aeration on the operation of cyclone diplegs fitted with trickle valves. Ind Eng Chem Res. 2004;43(18):5783-9. https://doi.org/10.1021/ie034213j.

Shaw DF, Walter RE. How FCCU trickle valves affect catalyst losses. Hydrocarb Process. 2007;5:75-84.

Shou MC, Leu LP. Energy of power spectral density function and wavelet analysis of absolute pressure fluctuation measurements in fluidized beds. Chem Eng Res Des. 2005;83(5):478-91. https ://doi.org/10.1205/cherd.04123.

Sinclair PG, Katterson AM, Klinzing GE, Bachovchin D. An analytical study of dipleg flow stability using a controlled non-mechanical valve. Powder Technol. 1983;36(2):259-66. https://doi. org/10.1016/0032-5910(83)85010-4.

Smolders K, Baeyens J. The operation of L-valves to control standpipe flow. Adv Powder Technol. 1995;6(3):163-76. https://doi. org/10.1016/S0921-8831(08)60525-7.

Smolders K, Geldart D, Baeyens J. The physical models of cyclone diplegs in fluidized beds. Chin J Chem Eng. 2001;9(4):337-47.

Sun GG, Shi MX, Shi AJ, Chen B, Zia L. Flow pattern of particles in a cyclone dipleg with a trickle valve. In: Kwauk M, Li J, Yang W-C, editors. Fluidization X. New York: United Engineering Foundation; 2001. p. 723.

van der Schaaf J, Schouten JC, van den Bleek CM. Origin, propagation and attenuation of pressure waves in gas-solid fluidized beds. Powder Technol. 1998;95(3):220-33. https://doi.org/10.1016/ S0032-5910(97)03341-X.

van der Schaaf J, Johnsson F, Schouten JC, van der Bleek CM. Fourier analysis of nonlinear pressure fluctuations in gas-solids flow in CFB risers-observing solids structures and gas/particle turbulence. Chem Eng Sci. 1999;54(22):5541-6. https://doi. org/10.1016/S0009-2509(99)00282-1.

van Ommen JR, Sasic S, van der Schaaf J, Gheorghiud S, Johnssone F, Coppensf M-O. Time-series analysis of pressure fluctuations in gas-solid fluidized beds-a review. Int J Multiphase Flow. 
2011;37(5):403-28. https://doi.org/10.1016/j.ijmultiphaseflo w.2010.12.007.

Wang J, Bouma JH, Dries HWA. An experimental study of cyclone dipleg flow in fluidized catalyst cracking. Powder Technol. 2000a;112(3):221-8. https://doi.org/10.1016/S0032 -5910(00)00296-5.

Wang SJ, Geldart D, Beck MS, Dyakowski T. A behavior of a catalyst powder flowing down in the dipleg. Chem Eng J. 2000b;77(12):51-6. https://doi.org/10.1016/S1385-8947(99)00144-8.

Wei YD, Liu RH, Sun GG, Shi MX. Fluidization behaviors of gas-solid two-phase flow in the standpipe. Chin J Proc Eng. 2003;3(5):385-9 (in Chinese).

Wei YD, Liu RH, Sun GG, Shi MX. Gas solids two phase flow in standpipe under negative pressure gradient. J Chem Ind Eng (China). 2004;55(6):896-901 (in Chinese).
Wei ZG, Yan CY, Jia MD, Song JF, Wei YD. Experimental analysis of pressure characteristics of catalyst powder flowing down a cyclone dipleg. Pet Sci. 2016;13(2):348-54. https://doi.org/10.1007/s 1218 2-016-0087-4.

Yang TY, Leu LP. Study of transition velocities from bubbling to turbulent fluidization by statistic and wavelet multi-resolution analysis on absolute pressure fluctuations. Chem Eng Sci. 2008;63:195070. https://doi.org/10.1016/j.ces.2007.12.024.

Zhang JY, Rudolph V. Flow instability in non-fluidized standpipe flow. Powder Technol. 1998;97(2):109-17. https://doi.org/10.1016/ S0032-5910(97)03395-0. 